\title{
APLIKASI SOFTWARE UNTUK MONITORING BAHAN BAKU PADA PERUSAHAAN PENGOLAH REMPAH-REMPAH
}

\section{SOFTWARE APPLICATION FOR RAW MATERIAL MONITORING APPLICATION IN SPICES PROCESSING COMPANY}

\author{
Mohamad Anas Sobarnas*, Suherwin, Ashari Imamuddin \\ *Program Teknik Informatika, Sekolah Tinggi Teknologi Muhammadiyah Cileungsi-Indonesia \\ *Jln. Anggrek No.25 Komplek Perum PTSC, Cileungsi, Bogor, Jawa Barat-Indonesia 16820
}

Informasi Artikel

Article History:

Submission: 24/04/2021

Revised: 08/0/2021

Accepted: 15/06/2021

\section{Kata Kunci:}

Monitoring; rancangan

software; bahan baku;

gudang.

\section{Keywords:}

Monitoring; software design;

raw materials; warehouse.

\section{* Korespondensi:}

Mohamad Anas Sobarnas anassobarnas87@gmail.com

\begin{abstract}
Abstrak
Kesesuaian pembelian bahan baku dengan proses produksi sangat krusial agar tidak terjadi penumpukan bahan baku. Hal ini akan menghilangkan masalah bahan baku yang tidak terpakai dalam proses produksi dan menjadi rusak tidak layak pakai. Penelitian ini bertujuan untuk merancang sebuah aplikasi perangkat lunak untuk monitoring material (bahan baku) yang ada di gudang. Perancangan perangkat lunak berbasis Unified Modeling Language (UML) ini telah menghasilkan suatu rancangan perangkat lunak untuk mendukung proses pengecekan bahan baku, permintaan barang, pembuatan PO, penerimaan barang, pengeluaran barang, dan pelaporan stock opname. Hasil evaluasi oleh calon pengguna perangkat lunak ini disimpulkan bahwa rancangan ini telah memenuhi kebutuhan perusahaan dan perlu diimplementasikan menjadi working system sehingga dapat mendukung proses bisnis perusahaan.
\end{abstract}

Abstract
The suitability of purchasing raw materials in accordance with the
production process is very crucial so that there is no accumulation of
raw materials. This will eliminate the problem of raw materials that are
not used in the production process and become damaged unfit for use.
This study aims to design a software application for monitoring
materials (raw materials) in the warehouse. This software design using
Unified Modeling Language (UML) was produced to support the process
of checking raw materials, requesting goods, making POs, receiving
goods, releasing goods, and reporting stock taking. The results of the
evaluation by prospective users of this software concluded that this
design had met the needs of the company and needed to be implemented
into a working system so that it could support the company's business
processes.

\section{PENDAHULUAN.}

Perkembangan teknologi informasi dan komunikasi saat ini sangat pesat. Terutama untuk menunjang perusahaan agar lebih maju dan berkembang. Sistem informasi yang dimaksud adalah suatu sistem kombinasi teratur dari orang-orang, hardware, software, jaringan komunikasi, dan sumber daya data yang mengumpulkan, mengubah, dan menyebarkan informasi dalam sebuah organisasi[1]. Oleh karena itu, kebutuhan sistem informasi dan data yang cepat, akurat dan tepat sangat penting untuk meningkatkan kinerja 
manusia, sehingga dapat mencapai tujuan yang diinginkan.

Persediaan material yang cukup dapat memperlancar proses produksi hingga barang jadi yang dihasilkan mempunyai kualitas yang tinggi. Tujuan memonitoring[2] untuk menekan biaya-biaya operasional seminimal mungkin sehingga akan mengoptimalkan kinerja perusahaan dan tidak akan terjadi penumpukan bahan baku di gudang. Bahan baku adalah bahan dasar yang dibutuhkan untuk proses produksi pada perusahaan manufaktur [3]. Bahan baku diperoleh dari proses pembelian dan digunakan pada proses produksi dengan mengalami perubahan bentuk dan sifat. Sehingga tidak terjadi kerusakan bahan baku pada saat dalam penyimpanan di gudang dan mengurangi resiko kerugian karena bahan baku rusak atau expired. Bahan baku atau rempah-rempah memiliki fungsi dan manfaat yang berbeda satu sama lainnya[4].

Kelebihan persediaan barang di gudang akan berpengaruh terhadap aktivitas di gudang[5]. Pada saat akan mencari bahan baku yang diperlukan untuk produksi lebih sulit mencarinya karena bahan baku yang bertumpuk-tumpuk. Untuk itu diperlukan adanya pencatatan dan pemonitoran bahan baku dengan baik agar tidak terjadi penumpukan bahan baku. Saat ini pencatatan bahan baku pada perusahaan pengolah rempah-rempah masih berbentuk manual dan berformat excel sehingga memungkinkan terjadinya human error (salah ketik) sehingga kurang efisien dan update. Dengan adanya perancangan software aplikasi monitoring material barang berbasis desktop Java yang menggunakan NETBEANS dan MYSQL dengan tujuan tampilan bersifat user friendly [6], sistem terintegrasi proses lebih efisien dan aman. Sistem ini sendiri dapat mengolah data dari bahan baku masuk, keluar, hingga dapat memesan bahan baku yang mulai habis atau bahan baku yang sedang dibutuhkan sehingga tidak mengganggu alur proses produksi. Dalam melakukan penelitian ini ada beberapa karya ilmiah sama yang menjadi referensi bagi peneliti[7][8][9].

\section{METODE}

Metode penelitian ini menggunakan metode kuantitatif deskriptif[10] yaitu dengan cara perancangan sistem yang terdiri dari pengumpulan dan analisis data, analisis kebutuhan sistem dan perancangan menggunakan $U M L$.

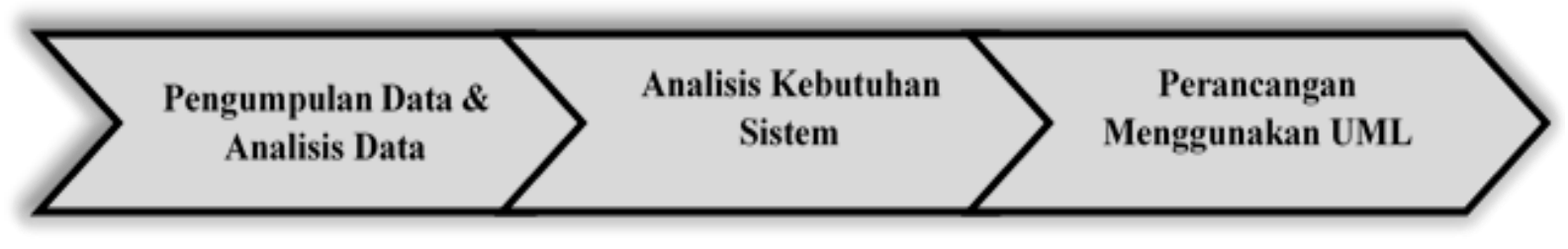

Gambar 1. Alir penelitian

Pengumpulan data yang dilakukan dengan cara mengumpulkan literatur, jurnal, paper dan bacaan-bacaan yang ada relevansinya dengan judul penelitian yang dijelaskan pada gambar 1 . Kemudian melakukan wawancara langsung kepada supervisor produksi, manager perusahaan dan manajer purchasing terkait dengan sistem pengendalian bahan baku (raw material). Selanjutnya melakukan perancangan sistem yang bertujuan untuk memberikan gambaran secara umum serta mengevaluasi sistem yang sedang berjalan.

Analisis data dilakukan untuk menunjang kebutuhan sistem aplikasi monitoring material barang yang dilakukan dengan metode analisis dan perancangan terstruktur, yang berorientasi kepada data dari perusahaan dan melakukan perbandingan sistem atau studi ilmiah tentang software aplikasi monitoring material barang mengenai fitur-fitur yang tersedia dan dibutuhkan. 
Analisis kebutuhan sistem mempelajari masalah dan kebutuhan dari organisasi untuk menentukan bagaimana orang, data, proses, komunikasi dan teknologi informasi dapat meningkatkan pencapaian bisnis[11]. Adapun analisis kebutuhan sistem yang dibutuhkan seperti proses input laporan yang lebih mudah dan aman, update-nya ketersediaan bahan baku (raw material) untuk digunakan dalam proses produksi, menampilkan atau mengecek ketersediaan bahan, tidak terjadinya kekurangan atau kehabisan bahan baku dalam proses produksi dan membuat sistem yang terintegrasi.

Perancangan sistem sendiri menggunakan perancangan $U M L$ berdasarkan beberapa pendapat, dapat disimpulkan bahwa $U M L$ [12][13][14] adalah untuk pemodelan software atau penggambaran yang dibentuk dalam simbol dan diagram, terdiri dari use case diagram, activity diagram, sequence diagram dan class diagram.

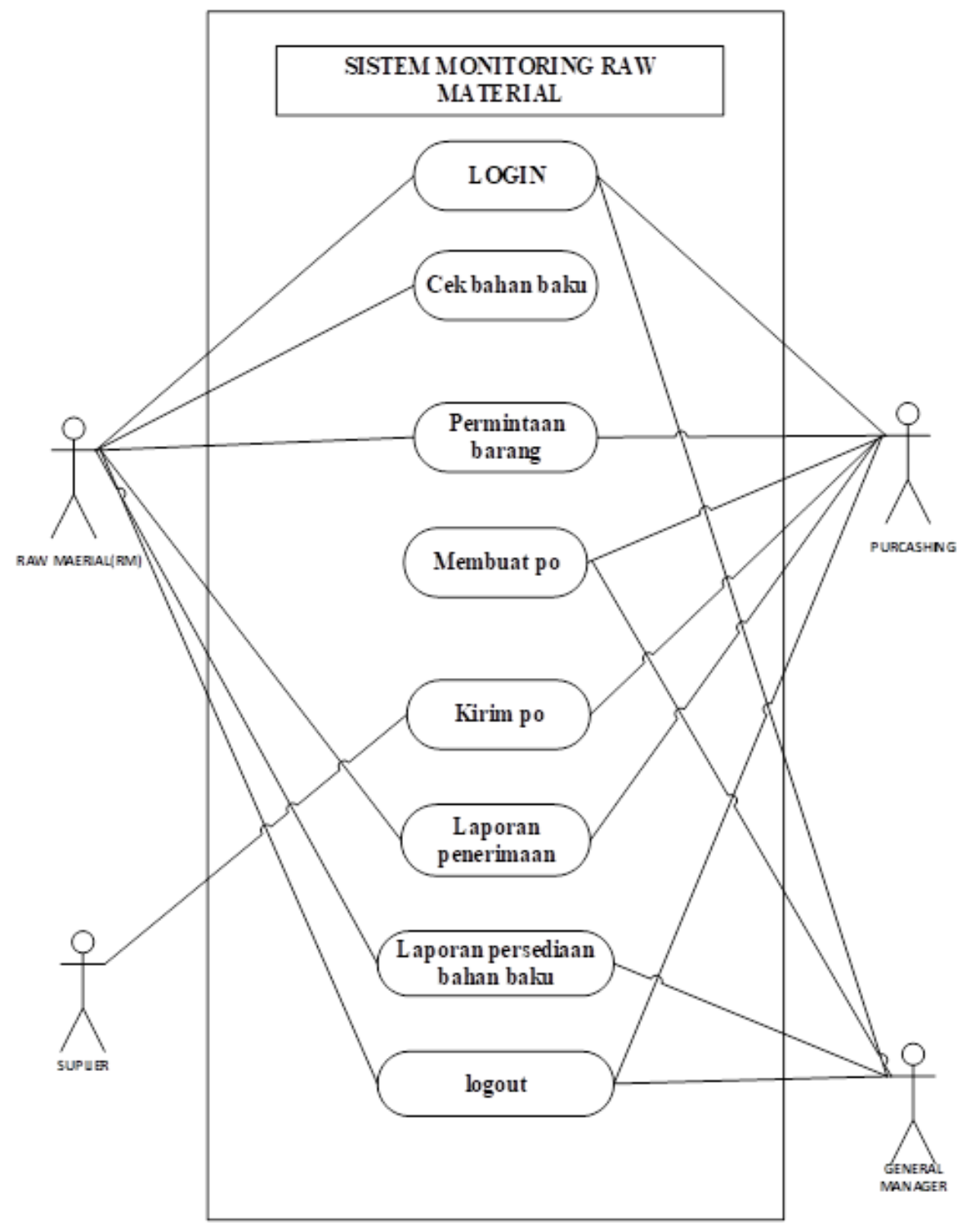

Gambar 2. Use case diagram

\section{HASIL DAN PEMBAHASAN}

Untuk memenuhi kebutuhan sistem agar dapat berjalan dengan baik maka dibutuhkan beberapa feature system. Aplikasi monitoring material barang ini memiliki fitur sebagai berikut: 
a. Pengecekan bahan baku.

Berfungsi membantu untuk melihat data bahan baku mana saja yang mulai habis atau yang sedang dibutuhkan untuk kebutuhan produksi.

b. Permintaan barang.

Berfungsi untuk membuat form permintaan barang yang habis atau yang sedang dibutuhkan dalam proses produksi ke bagian purchasing.

c. Pembuatan PO.

Digunakan untuk membuat Purchasing Order (PO) sesuai dengan permintaan barang yang telah dibuat dan telah disetujui oleh general manager.

d. Penerimaan dan pengeluaran barang.

Berfungsi untuk mencatat bahan baku yang masuk dan keluar dari gudang penyimpanan.

e. Pembuatan laporan stock opname.

Berfungsi untuk membandingkan data real dan data sistem yang ada.

\subsection{Use case diagram}

Berdasarkan gambar 2, use case diagram monitoring material barang yang dirancang memberikan gambaran fungsionalitas yang diharapkan dari sebuah sistem[15].

$>$ Sebuah sistem yang merupakan rancangan proses sistem monitoring material barang.

> Sistem Use case yang terdiri dari 4 (empat) faktor yaitu RM (raw material), purchasing, supplier dan general manager yang berperan di dalam sistem.

> Sistem Use Case monitoring material yang terdiri atas use case login, cek bahan baku, permintaan barang, membuat PO, laporan penerimaan, laporan persediaan bahan baku dan logout.

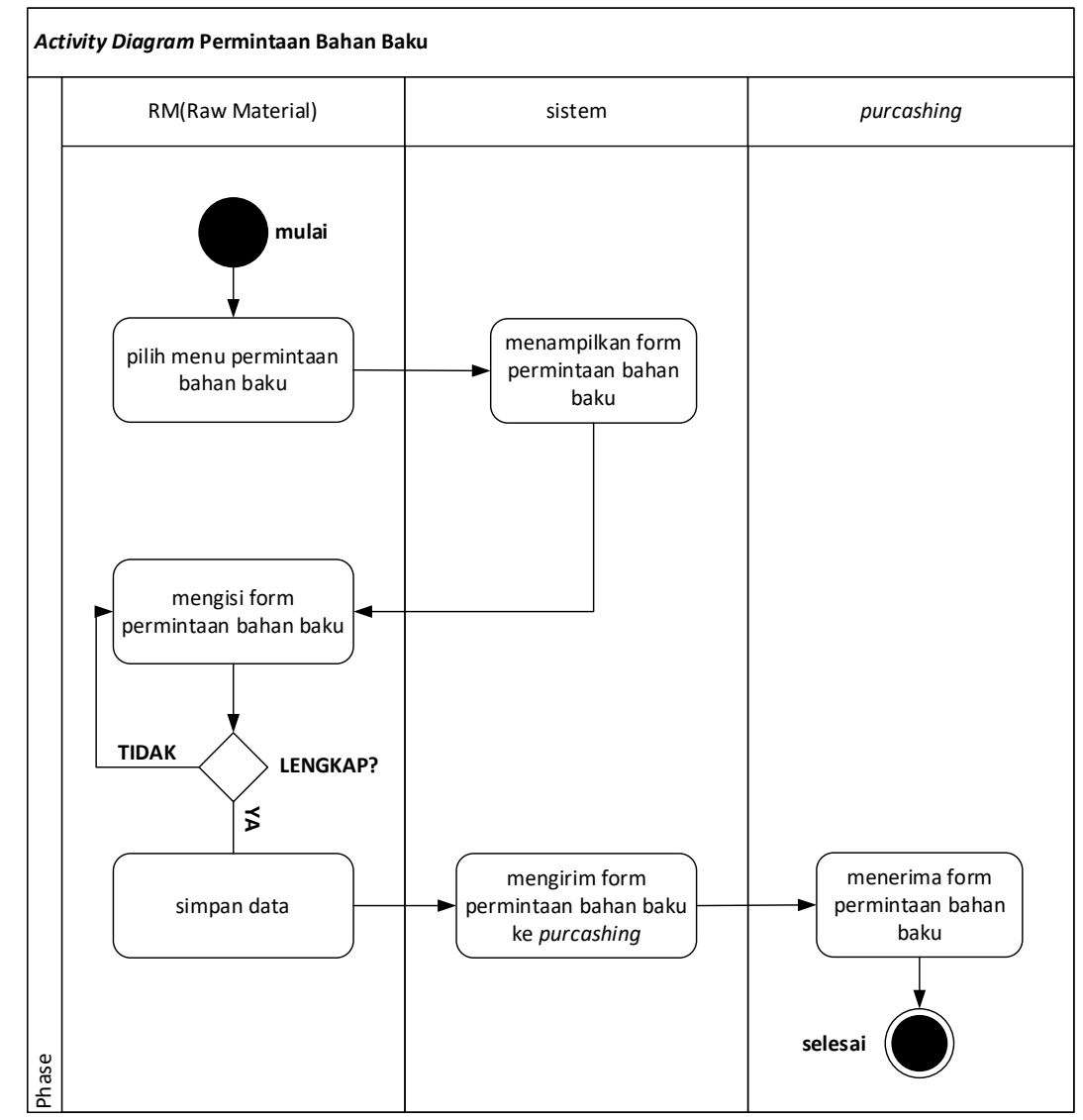

Gambar 3. Activity diagram permintaan barang 


\subsection{Perancangan activity diagram permintaan barang}

Activity diagram ini menggambarkan tentang proses dimana user akan membuat permintaan barang.

Keterangan gambar 3 menjelaskan aktivitas permintaan bahan baku oleh user raw material, pertama user memilih menu "permintaan bahan baku", kemudian user memilih button new, kemudian sistem menampilkan form input data permintaan bahan baku terdiri dari nama bahan baku, kode bahan baku, jumlah bahan baku, tanggal permintaan.

Data nama dan kode bahan baku telah tersedia dan dapat dipilih sesuai data yang dibutuhkan. Setelah terisi lengkap user bisa menyimpan dan print out, setelah tersimpan maka sistem akan memproses dan mengirim data form ke bagian purchasing.

3.3. Perancangan sequence diagram permintaan bahan baku

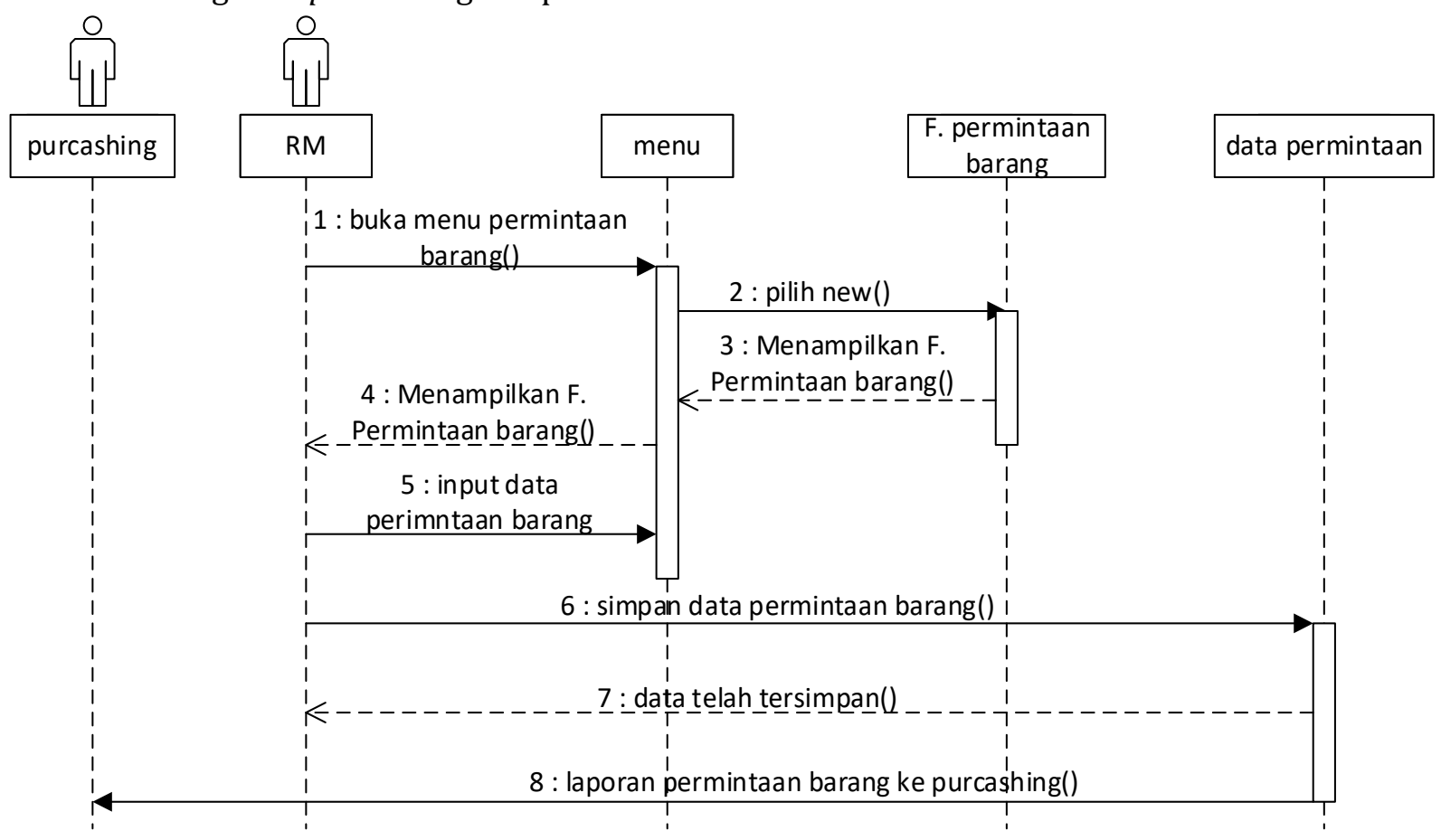

Gambar 4. Sequence diagram permintaan bahan baku

Proses sequence diagram permintaan barang dimulai oleh user dengan memilih menu permintaan barang pada halaman utama, di halaman muka permintaan barang user ditampilkan form input permintaan barang, selanjutnya user diperintahkan untuk input sesuai kolom isian, setelah selesai user bisa mengklik tombol simpan. Sistem akan menampilkan notifikasi "Data Telah Tersimpan" dan laporan akan terkirim ke bagian purchasing.

\subsection{Rancangan antarmuka (Interface)}

Selanjutnya akan dikemukakan rancangan antarmuka dengan pengguna (user interface) yang terdiri atas menu dan formulir input [16]. Rancangan menu adalah suatu diagram yang menggambarkan bagaimana suatu proses dihubungkan satu sama lain dalam waktu yang bersamaan. Rancangan menu digambarkan dengan sebuah state yang berupa komponen sistem yang menunjukan bagaimana kejadian-kejadian tersebut dari satu state ke state yang lain. 


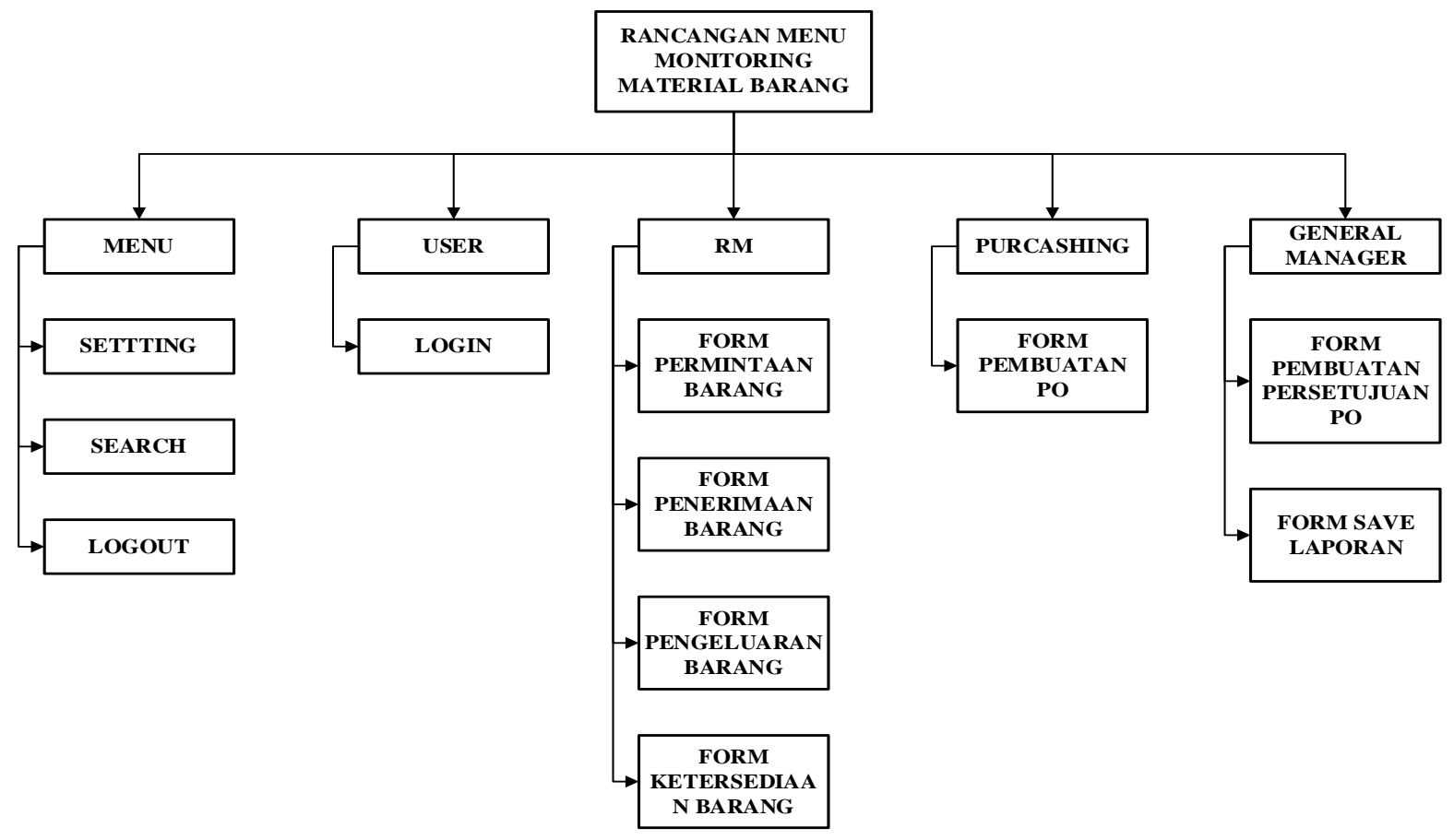

Gambar 5. Rancangan menu

\subsection{Rancangan form cek bahan baku}

Formulir cek bahan baku biasanya digunakan ketika akan melakukan kegiatan produksi atau hanya untuk melihat bahan baku mana saja yang mulai habis.

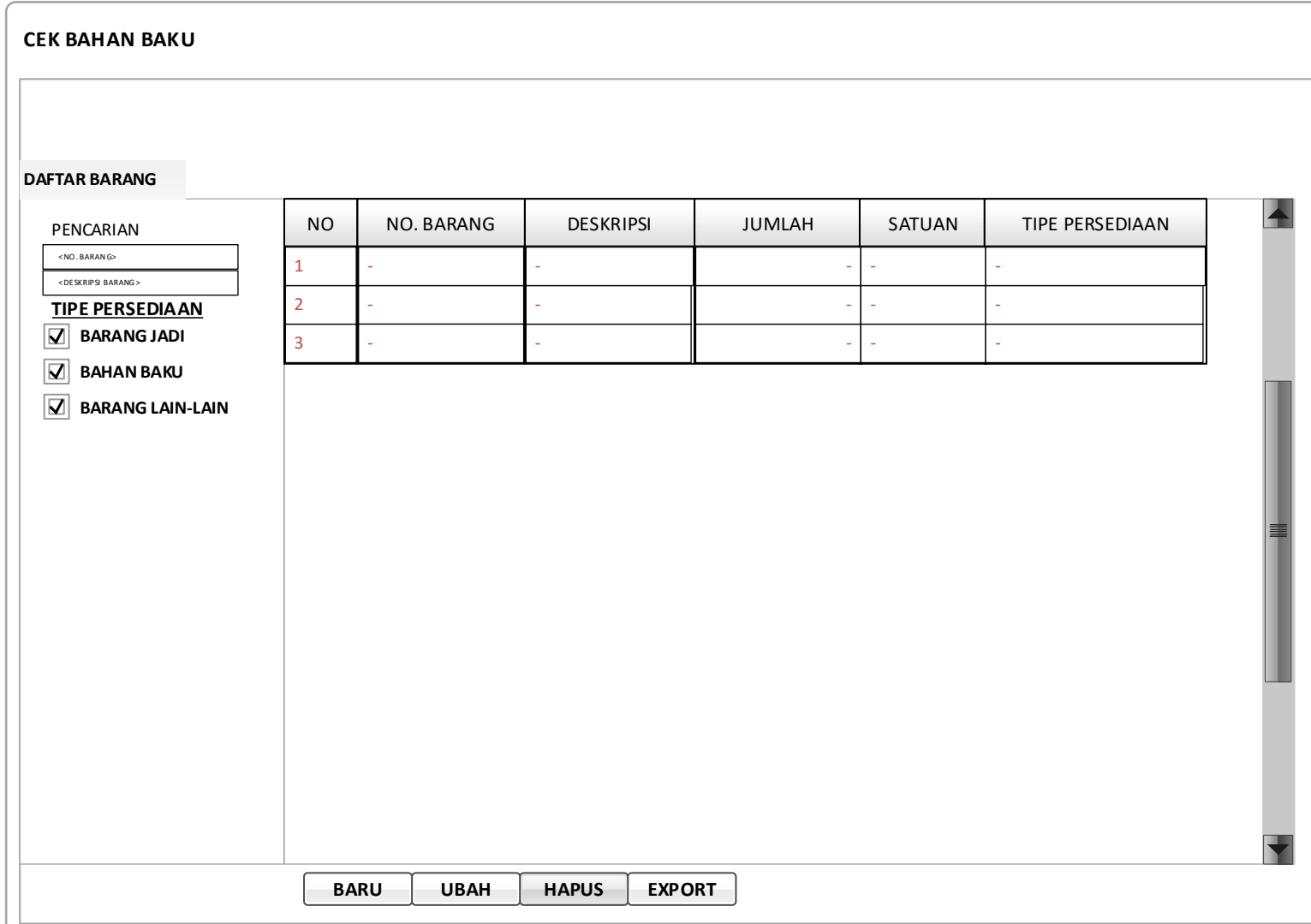

Gambar 6. Rancangan form cek bahan baku 
Jika suatu bahan mulai habis atau bahan baku yang akan digunakan tidak cukup maka akan dilakukan permintaan barang. Form ini sendiri menampilkan beberapa fitur yaitu menu pencarian barang agar lebih mudah dan cepat mencari suatu data barang. Tipe persediaan untuk membedakan antara tipe barang jadi, bahan baku dan barang lain-lain atau bahan pembantu packaging. Selanjutnya ada tampilan data barang yang terdiri dari nomor barang, deskripsi atau nama barang, jumlah, satuan, dan tipe barang.

\subsection{Perancangan konseptual class diagram}

Perancangan data digambarkan menggunakan conceptual class diagram, dengan tujuan untuk memberikan gambaran umum hubungan class pada sistem informasi monitoring material barang. Perancangan konseptual class diagram terdiri dari delapan class yang masing-masing class saling terhubung dan terdapat sembilan association yang menghubungkan ke delapan class tersebut. Konseptual class diagram pada gambar 5 menggambarkan hubungan antar tabel pada database dengan pemetaan entitas dan relasi antar tabel pada sistem informasi monitoring material barang.

\subsection{Validasi user}

Hasil evaluasi oleh calon pengguna perangkat lunak ini disimpulkan bahwa rancangan ini telah memenuhi kebutuhan perusahaan dan perlu diimplementasikan menjadi sistem nyata (working system) sehingga dapat mendukung proses bisnis perusahaan.

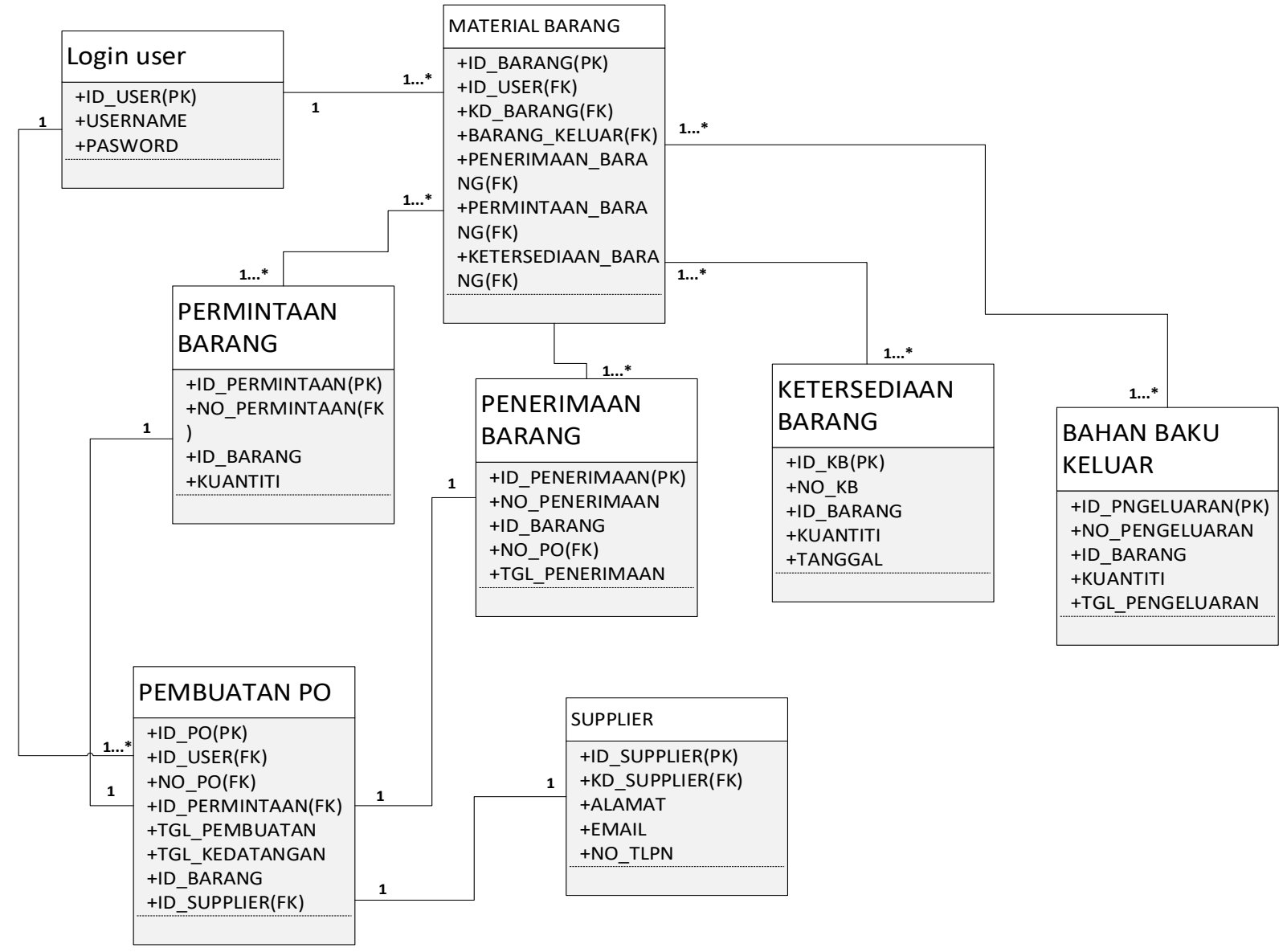

Gambar 7. Rancangan konseptual class diagram

\section{SIMPULAN}


Penelitian ini telah menghasilkan rancangan aplikasi software monitoring bahan baku pada perusahaan pengolahan rempah-rempah dengan menggunakan metode kuantitatif deskriptif yang telah digambarkan menggunakan perancangan UML (Unified Modeling Language). Rancangannya sendiri terdiri dari rancangan use case diagram, rancangan activity diagram permintaan barang, rancangan sequence diagram permintaan bahan baku, rancangan antarmuka (interface), rancangan form cek bahan baku dan perancangan konseptual class diagram. Hasil penelitian ini masih perlu diimplementasikan ke dalam bahasa pemrograman dan menjadi sebuah aplikasi software yang siap digunakan untuk memonitor ketersediaan dan kesesuaian bahan baku sehingga dapat diuji kelayakannya, oleh karena itu aplikasi software monitoring bahan baku perlu dikembangkan untuk memenuhi kebutuhan semua departemen terkait agar menjadi sistem yang bekerja (working system) sehingga dapat mendukung proses bisnis perusahaan. Selanjutnya pemrogram dapat menggunakan rancangan sebagai dasar pembuatan (pemrograman) aplikasi tersebut.

\section{DAFTAR PUSTAKA}

[1] E. Y. Anggraeni, "Pengantar Sistem Informasi - Elisabet Yunaeti Anggraeni - Google Buku," cv. Andi Offset(Penerbit Andi), 2017. .

[2] "Maksud / Arti Kata memonitor di Kamus Besar Bahasa Indonesia." .

[3] Y. Y. Siti Aisyah, Febrianty Febrianty, Hery Dia Anata Batubara, Indra Siswanti, Jony Jony, Supitriyani Supitriyani, Astuti Astuti, Ady Inrawan, Citrawati Jatiningrum, "Manajemen Keuangan - Google Buku," Yayasan Kita Menulis, 2020. .

[4] Yana, "Study jenis rempah - rempah dan pemanfaatannya di pasar tradisional angso duo," p. 125, 2018.

[5] P. Studi, T. Industri, F. R. Industri, P. Studi, S. Informasi, and F. R. Industri, "Panduan Penulisan Jurnal Rekayasa dan Industri ( Title Bahasa Indonesia ) Title in English," vol. xx, no. Penulis 1, pp. 3-5.

[6] Jubilee Enterprise, Belajar Java, Database, dan NetBeans dari Nol - Jubilee Enterprise Google Buku. jakarta: PT. Elex Media Komputindo, 2015.

[7] B. Setiadi, "APLIKASI MONITORING MATERIAL PERGUDANGAN PADA PT. PLN (Persero) AREA BANJARMASIN," Technol. J. Ilm., vol. 10, no. 4, pp. 179-193, 2019.

[8] D. Ilham, Laporan Kerja Praktek Sistem Informasi Monitoring Material Gudang pada PT . PLN ( PERSERO) 2014.

[9] A. S. Putra and O. M. Febriani, "SISTEM INFORMASI MONITORING INVENTORI BARANG PADA BALAI RISET STANDARDISASI INDUSTRI BANDAR LAMPUNG," 2013.

[10] M. P. Prof. Dr. A. Muri Yusuf, Metode Penelitian Kuantitatif, Kualitatif \& Penelitian Gabungan - Prof. Dr. A. Muri Yusuf, M.Pd. - Google Buku. JAKARTA: KENCANA, 2019.

[11] O. Muhamad Muslihudin, Analisis dan Perancangan Sistem Informasi Menggunakan Model Terstruktur dan UML - Muhamad Muslihudin, Oktafianto - Google Buku. Yogyakarta: CV. ANDI OFFSET, 2014.

[12] Erwin sutanto, Pemrograman Android Dengan Menggunakan Eclipse \& StarUML - Erwin Sutanto - Google Buku. surabaya:Airlangga University Press, 2020.

[13] D. A. M. Roni Habibi, Aplikasi inventory barang menggunakan QR code - Roni Habibi, Dinda Anik Masruro, Nuha Hanifatul Khonsa' - Google Buku. Bandung: Kreatif Industri Nusantara, 2020.

[14] A. Saputra, A. Imamuddin, and P. Sukamto, "Rancang Bangun Aplikasi Sistem Penjualan Case Study: Pt. X," INFOTECH J. Inform. Teknol., vol. 1, no. 2, pp. 78-86, 2020, doi: 10.37373/infotech.v1i2.67.

[15] A. Imamuddin, "An Integrated Information System Design for Managing National Hazardous Waste in Indonesia : A Proposal," An Integr. Inf. Syst. Des. Manag. Natl. Hazard. Waste Indones. A Propos., vol. 2, no. 1, pp. 158-164, 2021.

[16] A. Imamuddin, "An Enterprise Resource Planning System Solution for Small-Mid Size 
Mohamad Anas Sobarnas, Suherwin, Ashari Imamuddin

APLIKASI SOFTWARE UNTUK MONITORING BAHAN BAKU PADA PERUSAHAAN

PENGOLAH REMPAH-REMPAH

Enterprises : An Information System Development Case Study," J. Comput. Sci. Inf. Technol. Telecommun. Eng., vol. 2, no. 1, pp. 160-168, 2021, doi: 10.30596/jcositte.v2i1.6534. 